\title{
El sitio ICC-4: Un asentamiento precerámico en la quebrada de Inca Cueva (Jujuy, Argentina)
}

CARlos Aschero ${ }^{1}$

\begin{abstract}
RESUMEN
Se discuten en estas páginas algunos aspectos referidos a la delimitación de un piso de ocupación en la capa 2 del sitio Inca Cueva 4 (Departamento Humahuaca, Provincia de Jujuy, Argentina), su definición como un asentamiento de cazadores recolectores y sus correlaciones, tomando para ello como base los datos ya publicados, los de una reciente campaña y la primera datación radiocarbónica.
\end{abstract}

\section{Aspectos biogeográficos del asentamiento}

El emplazamiento del sitio Inca Cueva 4 ocurre en el sector medio de la quebrada de Inca Cueva a los $23^{\circ}$ Lat. S y $65^{\circ} 27^{\prime}$ Long. O, en relación con vertientes permanentes y comunidades vegetales que se identifican con las de matorral y bosquecillo de queñoas y vegetación compleja de los afloramientos rocosos de la tabulación de Ruthsatz y Movia (1975), entre los 3800 y 4000 m.snm. La presencia de queñuas (Polilepis tomentella) y agua permanente (dos recursos importantes para los asentamientos actuales en el borde oriental de la Puna jujeña) posibilitan la presencia en Inca Cueva de puestos dedicados al pastoreo, sin implementación alguna de recursos agrícolas locales.

A través de la información arqueológica los atractivos para el asentamiento en Inca Cueva 4 habrían sumado a la explotación de la madera de queñua, la disponibilidad de otros recursos vegetales para la dieta y las manufacturas; de una población faunística variada favorecida por los recursos de agua y la topografía; de recursos litológicos aptos para manufacturas y de reparo proporcionado por los numerosos abrigos naturales de las areniscas rojas del subgrupo pirgua. Entre estos abrigos se destaca el sitio Inca Cueva 1 (Gruta de Chulín o de Inca Cueva) que muestra una importante secuencia del arte rupestre local (Aschero 1979a).

1 Instituto de Antropología, Facultad de Filosofía y Letras, Universidad de Buenos Aires. 25 de Mayo 217, 1002, Buenos Aires, ARGENTINA.
Entre los otros recursos vegetales locales cabe mencionar el soldaque (Hypsocharis sp.), cactáceas (Thricocereus tarijensis, y del género Opuntia), helechos y gramíneas diversas, fibras y tallos de cortadera (Cortadera sp.) y de juncáceas. De las especies faunísticas presentes en el registro arqueológico, camélidos (vicuñas y guanacos) y cérvidos han virtualmente desaparecido, no así la vizcacha de la sierra (Lagidium sp.) que abunda en las peñas. De los recursos litológicos locales el principal es la cuarcita, en forma de guijarros provenientes de un conglomerado incluido en las areniscas y que han sido procesados en diversos talleres.

En relación al estudio faunístico se ha señalado que en un radio de $10 \mathrm{~km}$ el territorio de explotación desde Inca Cueva 4 cubriría otras comunidades vegetales y microambientes diversos (Mengoni 1982). Las prospecciones realizadas hasta el momento no han permitido localizar otros tipos de asentamiento dentro del radio indicado.

\section{Consideraciones sobre la estratigrafía y los hallazgos}

En 1979 se presentó la información preliminar sobre el asentamiento acerámico de Inca Cueva 4, asentamiento cuyo foco lo constituía una habitación de modelado intencional, excavada en el interior de un abrigo con pinturas rupestres. La capa cultural que constituía el piso de esta habitación (capa 2) contenía diversos artefactos y ecofactos en una matriz caracterizada por abundantes restos vegetales, con excelente conservación de otras materias orgánicas (Figura 1).

Los artefactos diagnósticos incluyen puntas de proyectil apedunculadas de limbo triangular corto y alargado (Figura 5); raederas laterales, convergentes $\mathrm{y}$ frontolaterales; raspadores de filo restringido y extendido; un perforador de base formatizada y microartefactos con retoque y/o microrretoque marginal, todos ellos elaborados sobre cuarcitas, basaltos y rocas silíceas (ftanitas), algunas de estas últimas con 
tratamiento térmico. Se suman a estos numerosos restos de cordeles de torsión Z-S-Z (con predominio de lana de camélido en las fibras utilizadas), cestería a la plana (plaited) y encordados (twinned) de tipos cerrado, envolvente y simple. Hay cuentas de collar recortadas sobre la columela de un caracol terrestre (Strophocheilus Megalobulimulus oblongus) y otras planas sobre valvas de Diplodon sp. Se recogieron también plumas embarriladas combinando unas blancas de ñandú con otras rojas de aves exóticas o bien pelos teñidos de rojo. Además se encontraron numerosos pendientes de pezuñas de cérvido con cordeles de amarre conservados. Para todos los aspectos vinculados con la ergología, que no se tratan aquí, ver Aschero (1979b), Pérez de Micou (1979) y Yacobaccio $(1979,1982)$.

Cuando en 1978 se emprendieron excavaciones en el abrigo se buscaba localizar remanentes de una capa con vegetales que había proporcionado restos de ocho inhumaciones y artefactos asociados, conformando un importante conjunto de vestigios acerámicos, extraídos en 1936 por Torres Aparicio (colección particular, San Salvador de Jujuy). El objetivo era obtener vestigios que facilitaran la datación y la comparación de la referida colección con el variado conjunto ergológico recuperado en el sitio Inca Cueva 7, datado por la muestra T-1773 en 4080 \pm 80 años AP (Aschero 1974; Aguerre et al. 1973 y 1975).

Las expectativas mencionadas fueron superadas por el hallazgo de la capa 2, estratificada por debajo de la lente con restos vegetales designada $1 \mathrm{~A}$, conservada en testigos adosados al fondo de la pared para los que se infiere correspondían a los remanentes de las extracciones de Torres Aparicio (Figura 4). Los distintos artefactos recogidos entre los restos vegetales de 1A se correlacionan con los hallazgos de Torres Aparicio: fragmentos de astiles con decoración incisa (geométrica) o lisos en cañas macizas (Chusquea sp.), una pluma embarrilada sujeta a un cordel, un fragmento de piel de camélido con costura y pintura roja, un bloque tabular con restos de pintura roja, torzales de cuero y cordelería en lana y fibra vegetal y restos óseos humanos aislados.

Entre las lentes con vegetales 1A y la capa 2, media un segmento de arena rojiza con vegetales desmenuzados (1B) que ofrece hallazgos esporádicos en los testigos de fondo de la pared. Los artefactos recogidos en campañas anteriores en el piso del abrigo, en el sector próximo al talud, donde los sedimentos $1 \mathrm{~B}$ aparecen expuestos, sugieren a su vez una posible relación con algunos rasgos de los artefactos de la capa 2 (artefactos líticos, cuentas de collar, colgantes de pezuña, cestería a la plana).

La ocupación de la habitación modelada en el piso estéril del abrigo y la posterior depositación de las inhumaciones se presentan como dos episodios diferentes de ocupación ligados por rasgos culturales compartidos pero cuya distancia temporal no ha sido aún calibrada. Por otra parte, la homogeneidad estilística de las pinturas rupestres del abrigo (agrupaciones de trazos, puntiformes, motivos abstractos geométricos simples) y su relación con las representaciones más antiguas registradas en las superposiciones del sitio Inca Cueva 1 (Grupo Estilístico A) proporcionan datos de apoyo para tal inferencia (Aschero 1979 a y b).

La habitación modelada sobre la arena roja estéril de la capa 3 contenía dos pozos o "bodegas" interiores (Z-Y en Figura 1) colmados de restos vegetales y diversos artefactos y pequeños pozos periféricos también con restos vegetales. Las acumulaciones de restos vegetales en sedimento carbonoso que constituye la capa 3 se extienden fuera del límite de la habitación. La distribución de artefactos y ecofactos sumado a lo anterior sugieren la existencia de un piso de ocupación extendido a ambos lados de la habitación. En el interior de esta se concentraba la mayor cantidad de manufacturas y dos fogones playos, de escasa potencia y sin contorno de piedras.

Entre los restos faunísticos presentes en el interior y borde de la habitación (procedentes de las campañas 1978/79), Mengoni determinó la presencia de restos óseos y fibra de Lagidium viscacia y Chinchilla sp. (NISP: 202; MNI: 16); huesos de Ctenomys sp. (NISP: 4) y de Artiodactyla (Flia., gen. et. sp. indet.; NISP: 11). La presencia de Camelidae (gen. et. sp. indet.) se ha detectado a través de fibra (vellón) y la Hippocamelus sp. por escasos restos óseos (NISP: 6) y fibra; esta última representada por una pequeña acumulación de pelos en el fondo de la habitación. Se suman otros escasos restos óseos de Canidae (gen. et. sp. indet.; NISP: 1), de Nothura sp. (NISP: 3) y de un batracio no identificado (Mengoni 1982: 1).

El análisis faunístico ha permitido inferir que vizcachas y chinchillas eran traídas enteras al sitio. La escasa representatividad de Hippocamelus y Artiodactyla en general (considerando lo adecuado 
del hábitat local) sugería: 1) la existencia de otras estructuras de habitación o de evacuación fuera del sector excavado, 2) el transporte solo de partes de los animales trozados fuera del sitio, y 3 ) un consumo interfamiliar y compartido (fraccionamiento y repartición de la pieza) (Mengoni 1982: 5).

Un primer fechado radiocarbónico de Inca Cueva 4 obtenido sobre una muestra de carbón vegetal de uno de los núcleos de fogón en el piso del recinto habitacional (ver Figura 1) ofrece una alternativa con respecto a la ubicación temporal sugerida en el primer informe (Aschero 1979b). La muestra procesada por el Dr. Alonso en el Instituto Rocasolano de Madrid proporcionó la siguiente datación: Muestra CSIC-498: 9230 \pm 70 años AP (7280 años AC).

Esto lleva a rever las correlaciones antes sostenidas con sitios precerámicos tardíos en zonas próximas de la Puna oriental y Norte Grande chileno.

Una nueva campaña realizada en 1982 permitió ampliar la base de datos disponibles para estas correlaciones. $^{2}$

\section{Nuevos datos sobre el piso de ocupación de capa 2}

Los resultados obtenidos en las campañas 1978/79 planteaban una serie de interrogantes en torno a tres ítems principales: a) la existencia de otras estructuras de planta y la continuidad del piso con vegetales en el exterior de la habitación modelada; b) la relación de semejanza entre las tecnofacturas de IA y $2 ; \mathrm{c}$ ) el hallazgo de otros indicadores de relación entre las pinturas rupestres y las ocupaciones del abrigo. La obtención de información sobre estos estaba sujeta a la delimitación de sectores no perturbados por las extracciones de 1936. La reactivación de los perfiles de 1979 proporcionó dos frentes para seguir la capa 2 y detectar perturbación, ampliándose la excavación hacia los sectores E-H/2-6 hacia el frente sur y L-M/4-6 hacia el norte (ver Figura 1).

Respecto al primero de los ítems citados, los resultados de esta última campaña proporcionan una importante información adicional. Hacia el frente sur la capa 2 (con restos vegetales en sedimentos

2 La campaña, financiada por la Facultad de Filosofía y Letras de la Universidad de Buenos Aires, contó con la participación de H. Yacobaccio, E. Cúneo, V. Horwitz, P. Mancini, G. Platania, N. Ratto y H. Vidal. carbonosos y/o abundantes carbones sueltos) continúa en todas las cuadrículas excavadas mostrándose muy delgada hacia la zona del talud y potente hacia la pared. Hacia el sector 4-5 está compuesta por dos camadas de vegetales que pueden diferenciarse por su estado y composición, sin mediación de sedimentos interestratificados. Esta zona E-H muestra artefactos líticos dispersos, muy pocos formatizados (raspadores frontales y artefacto burilante) con escasos desechos de manufacturación que se concentran en $\mathrm{H} 2-3$, en continuidad con los registros del fondo de la habitación.

En esta misma zona, en las cuadrículas próximas al talud, se observa la presencia de concentraciones con vegetales en mal estado de conservación, residuos de una actividad no determinada. La ubicación de estos en el borde externo de la habitación y contra la pared de un nuevo pozo-depósito ubicado en F5-6 (pozo "F") permite asociar esta estructura de cavado con el piso de ocupación. Sus dimensiones $(65 \mathrm{x} 80 \mathrm{~cm}$ y $40 \mathrm{~cm})$ de profundidad son semejantes a las del pozo "Y" del interior de la habitación. Su contenido incluye diversos restos vegetales de recolección, troncos de queñua, cordeles de lana y dos costillas humanas. Faltan los elementos suntuarios (pendientes, cuentas y plumas embarriladas) que caracterizaban los pozos del interior de la habitación (Aschero 1979b). Entre la habitación y el pozón "F" hacia el borde del talud se ubicaron cuatro agujeros con un diámetro variable entre 10 y $14 \mathrm{~cm}$ y entre 15 a $20 \mathrm{~cm}$ de profundidad, posibles remanentes de postes clavados verticalmente en el sedimento arenoso y muy próximos entre sí; el relleno de éstos lo constituía el sedimento con vegetales y carbones de la capa 2.

Hacia el frente norte la apertura de la zona L-M abarcó un extremo de la habitación y permitió ubicar en su borde externo una lente de basuras y un nuevo pozo-depósito de mayores dimensiones que los anteriores; éste fue designado " $\mathrm{M}$ " y excavado parcialmente. La referida lente ("L" en Figura 1) presenta un alto contenido de ceniza y carbones, abundantes restos vegetales (gran cantidad de corteza de queñua, tallos y hojas de soldaque y otros mal conservados), astillas de huesos largos y algunos artefactos líticos que incluyen otra punta de proyectil triangular apedunculada de fractura incompleta. $\mathrm{La}$ presencia de vegetales no quemados entre cenizas y carbones sugiere que se trata de la evacuación del contenido de los fogones interiores de la habitación cuando éstos no estaban activos, explicando también 


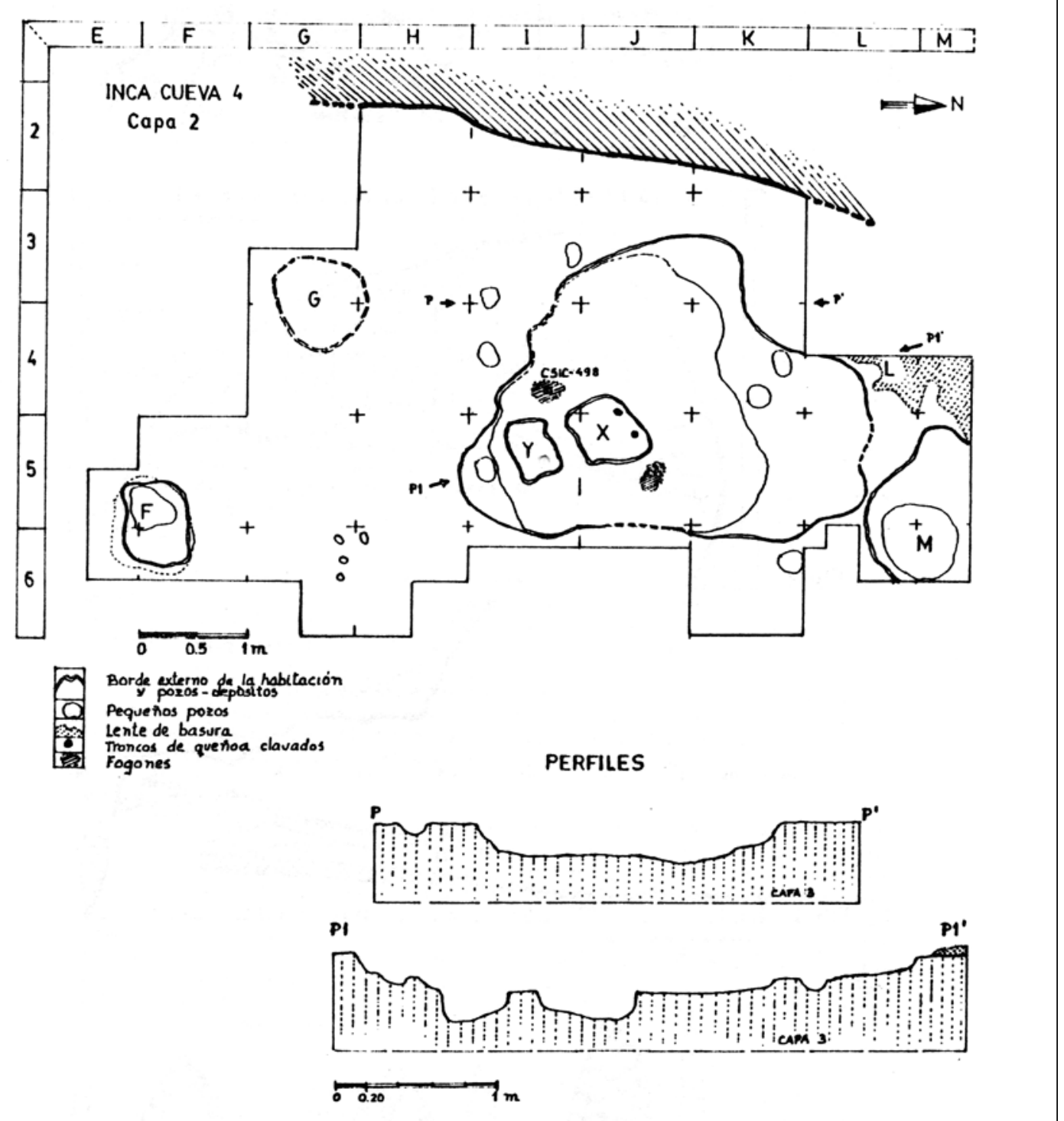

Figura 1. Inca Cueva 4, capa 2 y perfiles de las capas 2 y 3.

la escasa potencia de los mismos. El pozo "M" (de $1.10 \mathrm{~m}$ x $0.50 \mathrm{~m}$ de profundidad) proporcionó abundantes restos de cordeles de lana, torzales de cuero y vegetales de recolección. En la zona cumbre se recogió otra punta triangular apedunculada en cuarcita y en la base fragmentos de pieles curtidas, vellones de lana de camélido y pelos de cérvido. Estos últimos hallazgos son importantes porque repiten gran parte de los residuos recogidos en el interior de la habitación.

El conjunto de estos hallazgos indica: 1) la continuidad de la capa 2 con sus restos vegetales en los sectores periféricos de la habitación; 2) la existencia de otras estructuras de planta vinculadas a esta capa (pozos-depósito, lente de basura, agujeros de postes); 3) la disminución en la frecuencia de hallazgos de artefactos líticos fuera del sector de la habitación; 4) la recurrencia en el relleno de los pozos exteriores de ecofactos y artefactos semejantes a los recogidos en el interior de la habitación, en el piso o en los pozos-depósito. Estas observaciones verifican que se trata de un piso de ocupación expresado por la organización espacial de las actividades, inferidas a partir de la distribución de los vestigios y por las zonas de evacuación de los residuos. 

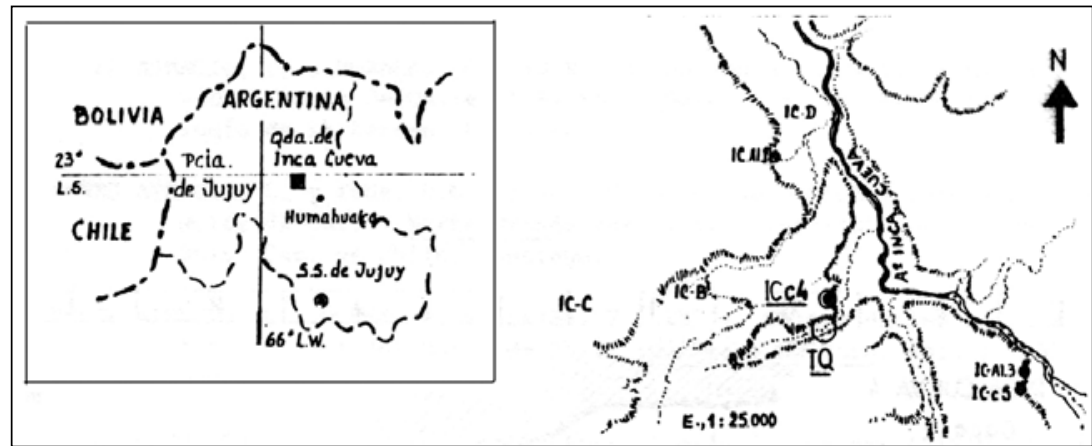

Figura 2. Ubicación de Inca Cueva 4 en la Provincia de Jujuy.

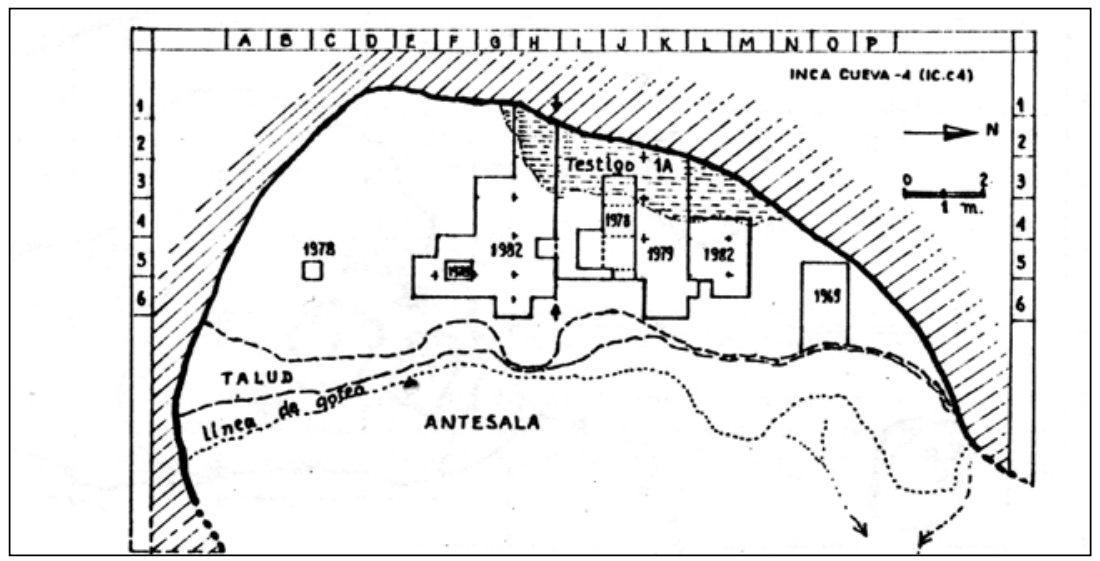

Figura 3. Excavación de Inca Cueva 4.

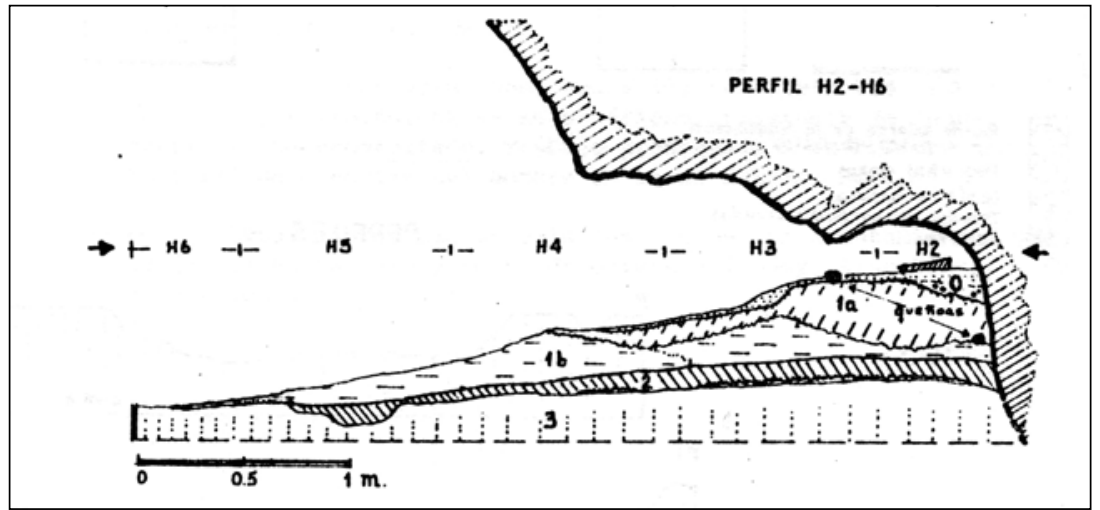

Figura 4. Inca Cueva 4, Perfil H2-H6.

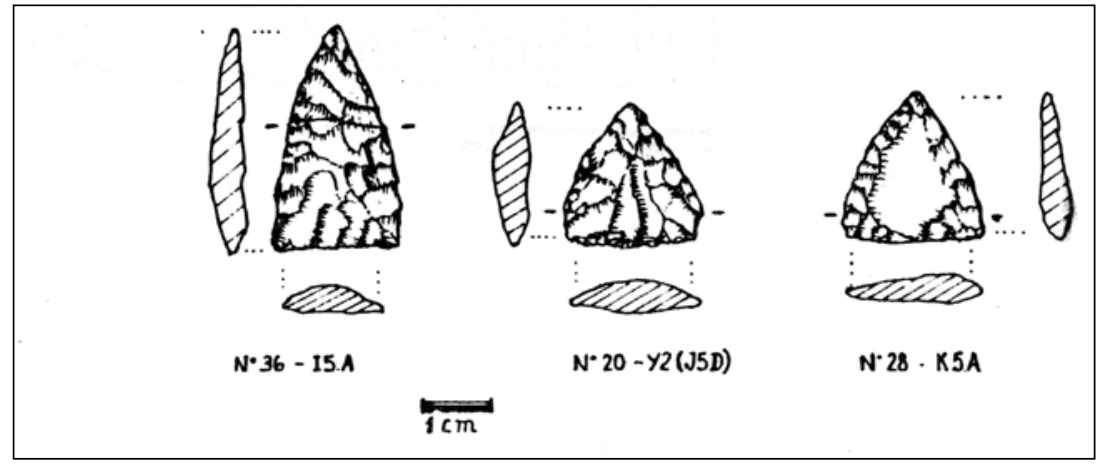

Figura 5. Puntas de proyectil apedenculadas de Inca Cueva 4. 
Respecto al segundo ítem antes citado la reducida cantidad de artefactos recogidos en capa, en las lentes con vegetales de $1 \mathrm{~A}$ y en $1 \mathrm{~B}$, no permite establecer mayores relaciones con la capa 2. Se observó, sin embargo, la existencia de un pozo-depósito ("G" en Figura 1) con las mismas características de los anteriores, que recortaba la capa 2 , rellenada con restos vegetales de las lentes $1 \mathrm{~A}$. En su contenido predominan los torzales de cuero, observándose un cuidadoso revestimiento de paja en la base del pozo.

Para el tercer ítem planteado se han sumado en esta campaña nuevos indicadores en relación con el arte rupestre. Restos de pigmento blanco, un fragmento de roca tabular quemada con pintura roja y vellones de lana de camélido teñidos con rojo fueron recogidos en capa 2. Estos se suman al artefacto con pintura roja, a los restos de pigmento blanco y al hisopo citados en el informe anterior (Aschero 1979b). No se hallaron restos de las pinturas afectadas por la exfoliación de la arenisca, excavando al pie de las mismas; se deduce que estos se han desintegrado o bien han sido removidos con los sedimentos extraídos por Torres Aparicio. Se mantiene por lo tanto la hipótesis de que una u otra ocupación (capas 2 y 1A) estarían vinculadas con la ejecución de las pinturas.

\section{Características del asentamiento}

Cuando en 1979 se integraron los hallazgos de Inca Cueva 4 en términos de un asentamiento acerámico, se pusieron en relación la habitación, los vestigios recogidos en la base del talud o antesala del abrigo y los grandes artefactos de tipo chopper recogidos al pie de las queñuas de un bosquecillo que se inicia en las proximidades del sitio (Torrentera de las Queñuas; “TQ” en Figura 2). Se designó entonces: 1) un sector de habitación dentro del abrigo (dividida en un "espacio de actividad interior" y un "espacio reservado" dentro del recinto); 2) un espacio de actividad exterior en el sector de la antesala, y 3) un sector de explotación próxima en la Torrentera de las Queñoas. Los análisis llevados a cabo por Yacobaccio sobre los artefactos líticos con rastros de utilización y sustancias adheridas más lo observado en la reciente campaña han permitido establecer nuevas opciones en ese primer esquema.

Se ha sugerido para la zona de habitación una subdivisión en: 1a) un "área de actividad específica" donde se harían tareas relacionadas con el laboreo de pieles y vegetales no leñosos; 1b) un "área de depositación aglomerada" correspondiente a la zona de los pozos y fogones internos de la habitación, y 1c) un "área de depósito aglomerado" correspondiente a uno y otro pozo del interior del recinto (Yacobaccio 1981). La primera de estas subdivisiones equivale espacialmente al anterior "espacio reservado", designación que debe ser dejada de lado en razón de lo inferido a través del microanálisis, confirmado por la distribución de los hallazgos en la zona E-H y por la presencia de restos de pelo de cérvido en el fondo de la habitación. El uso del término "depósito aglomerado" implica que se trata de un relleno, sin organización alguna en los elementos depositados. Lo que sí existe es una cierta selección entre los artefactos abandonados en estos pozos-depósito interiores (elementos del adorno personal) respecto a los exteriores. A esta área de habitación con sus subdivisiones debe agregársele ahora una "subárea de evacuación próxima" representada por la lente de basura. Los pozos exteriores serían también "depósitos aglomerados", con las diferencias de contenido ya apuntadas respecto a los del interior de la habitación.

Las otras áreas que integran el asentamiento pueden ser sostenidas. En la antesala se ha vuelto a observar la presencia de artefactos líticos, guijarros y bloques tabulares que tendrían que ver con actividades ejecutadas a cielo abierto. Debe señalarse, sin embargo, que tanto aquí como en la capa 0 de la excavación (constituida por excrementos de roedores) se recogieron este año escasos fragmentos de cerámica aún no clasificados; no obstante, puede afirmarse que no ha habido en la cueva una ocupación de grupos con cerámica. La presencia de fragmentos de guijarros y lascas de cuarcita con retalla marginal en capa 2 , los troncos y la abundancia de corteza de queñua en los pozos-depósito observados en esta última campaña llevan a insistir en la hipótesis de que esos artefactos de tipo chopper recogidos al pie de las queñuas están funcionalmente ligados a la explotación del bosquecillo por parte de los ocupantes del abrigo.

La presencia de vegetales en las distintas estructuras de planta indica la existencia de una recolección variada y si bien no se posee aún un diagnóstico completo de las especies no hay evidencia de cultígenos. Entre los vegetales comestibles se destaca por su abundancia el soldaque, conocido en la actualidad como un estimulante para las afecciones de la altura y para uso medicinal. Si bien los tubérculos son posibles 
de recoger durante todo el año en la zona del abrigo, los tallos y hojas se secan en otoño e invierno, por lo tanto la presencia de tallos y hojas entre los vegetales recogidos en la capa 2 indican su recolección en épocas de primavera o verano. Estos tubérculos fueron encontrados por Fernández en las excavaciones efectuadas en Inca Cueva 1 (Fernández 1969-70). Las gramíneas de capa 2 son identificables con las especies Stipa, Festuca y Bromus sp., esta última con especímenes en floración, lo que refuerza la hipótesis de una ocupación de fin de primavera o verano. Otros vegetales locales identificados son la cortadera, las cactáceas y una leguminosa (Lupinus sp.). Los fragmentos de caña (Chusquea sp.) son alóctonos, posiblemente obtenibles en tierras bajas orientales.

\section{Correlaciones}

El fechado radiocarbónico obtenido (que será controlado con otras dataciones en curso) indicaría un asentamiento temprano en relación a los pocos fechados disponibles para el Precerámico de la Puna argentina. La correlación inmediata son los hallazgos de la capa E3 del sitio CH III de Huachichocana con dataciones de $10200 \pm 420$ (GAK 5847), 8420 \pm 530 (P-2280) y 9340 130 (P-2236) años AP (Fernández Distel 1980). De esta capa Fernández Distel dio a conocer puntas apedunculadas triangulares junto a otras de limbo lanceolado. La ilustrada en su informe de 1974 bajo el n ${ }^{\circ} 866$ responde al patrón morfológico de las de limbo triangular corto de Inca Cueva 4, pero es, como las restantes triangulares, de mayor tamaño y está formatizada mediante lascados más anchos y cóncavos que las de este sitio, según lo observado en el Museo del Pucara de Tilcara (Fernández Distel 1974; Aguerre et al. 1975).

Componentes tempranos con puntas triangulares apedunculadas comparables a las de Inca Cueva 4 han sido localizados y datados en las estratigrafías de Tuina y San Lorenzo, en la serranía de Calama y zona de San Pedro de Atacama, respectivamente; las dataciones son de 10820 años AP para Tuina y entre 10400 a 9960 años AP para San Lorenzo (Núñez 1980 y com. pers.). Hallazgos más distantes en los complejos IIb a IId de Guitarrero y en la base de la secuencia de Pachamachay, con cronologías tempranas del orden de los 8000 a 11000 AP, avalan la posición temprana de las puntas triangulares en el área andina (Lynch 1980: 300; Rick 1980: 316). San Pedro Viejo en el Norte Chico chileno marca un punto más sureño con persistencia de puntas triangulares desde épocas tempranas (Rivera y Ampuero 1971).

El patrón de la habitación de Inca Cueva 4 con sus pozos-depósito no ofrece objeciones mayores para una ubicación temprana, conociendo las cronologías de Tiliviche 1B y Tarapacá 14 A en el Norte Grande, con habitaciones semisubterráneas modeladas, a cielo abierto. Las habitaciones más tempranas de Tiliviche estarían relacionadas con la fecha de 7850 AP (Núñez y Moragas 1977-78: 59), mientras que las de Tarapacá 14 A (casa 5) habrían sido habitadas desde el 6430 AP (Núñez y True 1974). Este patrón se generaliza para los complejos tardíos precerámicos del área del río Loa y de San Pedro de Atacama incorporando paredes de piedra o laja en sitios como Caleta Huelén 42, Tulan 52 y Puripica 1 (Núñez et al. 1974; Núñez 1981).

La similitud de la cordelería y cestería de Inca Cueva 4 con las de los complejos tempranos de Guitarrero es notable y en este sentido apoya la hipótesis de Adovasio sobre el temprano desarrollo de estas técnicas en América (Adovasio y Maslowski 1980: 287). Un segundo aspecto es la selección de lana de camélido como fibra de neto predominio en Inca Cueva 4, lo que marca una diferencia con la cordelería temprana de Guitarrero (Adovasio y Maslowski 1980: 262). La implementación de la lana para abastecer tecnologías específicas en Inca Cueva 4 implicaría (de confirmarse la cronología) una temprana dependencia de estos grupos andinos con respecto al camélido.

La evidencia disponible para sostener desplazamientos estacionales desde o hacia Inca Cueva 4 es aún débil. Las plumas de aves exóticas, las cañas utilizadas y algunas rocas (como el basalto, los sílices y calcedonias) que pueden proceder respectivamente de tierras bajas orientales o del piso precordillerano puneño, no son conclusivas para suponer territorios anuales muy extendidos puesto que bien pueden provenir de tempranos intercambios. Lo que sí puede enfatizarse es que el asentamiento de Inca Cueva 4 dispone de: a) recursos locales suficientes para las necesidades de la dieta y las manufacturas; b) que la densidad de artefactos recogidos no presupone un grupo grande de personas y/o estadías prolongadas, y que c) en contraste con esto último, la organización del piso habitacional con sus diversas estructuras de cavado y con la "limpieza" o evacuación de residuos de la 
habitación en los pozos-depósito, sugiere una reutilización periódica del sitio o un prolongado tiempo originalmente previsto para su ocupación. Rituales vinculados con el arte rupestre o la funebria quedan como probables variables a tomar en cuenta en la interpretación de la índole del asentamiento.

\section{REFERENCIAS CITADAS}

ADOVASIO, J. y R. MASLOWSKI, 1980. Cordage, basketry and textiles. En Guitarrero cave. Early Man in the Andes. T. Lynch (Ed.). Studies in Archaeology, Academic Press.

AGUERRE, A. M., A. FERNANDEZ DISTEL y C. ASCHERO, 1973. Hallazgo de un sitio acerámico en la quebrada de Inca Cueva (Provincia de Jujuy). Relaciones (N.S.) VII.

1975. Comentarios sobre nuevas fechas en la cronología arqueológica precerámica de la Provincia de Jujuy. Relaciones (N.S.) IX .

ASCHERO, C., 1974Ms. Contextos acerámicos de las quebradas de Huachichocana e Inca Cueva: Correlaciones e indicadores.

1979a. Aportes al estudio del arte rupestre de Inca Cueva 1 (Departamento Humahuaca, Jujuy). Actas de las Jornadas de Arqueología del Noroeste Argentino. Universidad del Salvador, Buenos Aires.

1979b. Un asentamiento acerámico en la quebrada de Inca Cueva. Informe preliminar sobre el sitio Inca Cueva 4. Actas de las Jornadas de Arqueología del Noroeste Argentino, Universidad del Salvador, Buenos Aires.

FERNANDEZ DISTEL, A., 1974. Excavaciones arqueológicas en las cuevas de Huachichocana, Departamento Tumbaya, Provincia de Jujuy, Argentina. Relaciones (N.S.) VIII.

FERNANDEZ, J., 1969/70. La recolección de bulbos, rizomas y tubérculos entre los cazadores de la Puna. Anales de Arqueología y Etnología XXIV-XXV. Universidad Nacional de Cuyo, Mendoza.

LYNCH, T. (Ed.), 1980. Guitarrero cave. Early Man in the Andes. Studies in Archaeology. Academic Press.

MENGONI, G., 1982Ms. El hombre prehistórico en la Puna argentina, su relación con la fauna. Ponencia presentada ante la Primera Reunión Nacional de Ciencias del Hombre en Zonas Aridas, Mendoza.

NUÑEZ, L., 1980. Cazadores tempranos en los Andes Meridionales. Boletín de Antropología Americana 2.
1981. Asentamientos de cazadores recolectores tardíos de la Puna de Atacama: Hacia el sedentarismo. Chungara 8.

NUÑEZ, L. y C. MORAGAS, 1978. Ocupación arcaica temprana en Tiliviche, norte de Chile (I Región). Boletín del Museo de Arqueología de La Serena 16.

NUÑEZ, L. y D. TRUE, 1974. Un piso habitacional temprano en el norte de Chile. Norte Grande I (2).

NUÑEZ, L., P. NUÑEZ y V. ZLATAR, 1974. Caleta Huelén 42: Una aldea temprana del norte de Chile. Hombre y Cultura 2 (5).

PEREZ DE MICOU, C., 1979. Informe sobre el material de cestería y cordelería pertenecientes al sitio ICc4 (Provincia de Jujuy). Actas de las Jornadas de Arqueología del Noroeste Argentino. Universidad del Salvador, Buenos Aires.

RIVERA, M. y G. AMPUERO, 1971. Secuencia arqueológica del alero rocoso de San Pedro Viejo-Pichasca (Ovalle, Chile). Boletín del Museo Arqueológico de La Serena 14.

RICK, J., 1980. Prehistoric hunters of the High Andes. Studies in Archaeology. Academic Press.

RUTHSATZ, B. y C. MOVIA, 1975. Relevamiento de las estepas andinas del noroeste de la Provincia de Jujuy. FECIC Ed. Buenos Aires.

YACOBACCIO, H., 1979. Análisis funcional de los instrumentos líticos de Inca Cueva 4 (nota preliminar). Actas de las Jornadas de Arqueología del Noroeste Argentino. Universidad del Salvador, Buenos Aires.

- 1981Ms. Análisis espacial del sitio Inca Cueva 4. Informe al CONICET.

Ms. Consideraciones sobre los asentamientos de cazadores post-pleistocénicos en zonas áridas (Provincia de Jujuy, Argentina). Trabajo presentado a la Primera Reunión Nacional de Ciencias del Hombre en Zonas Aridas. Mendoza.

1984. Aproximación a la función de los asentamientos precerámicos en la Puna y su borde oriental (Jujuy, Argentina). En este volumen. 